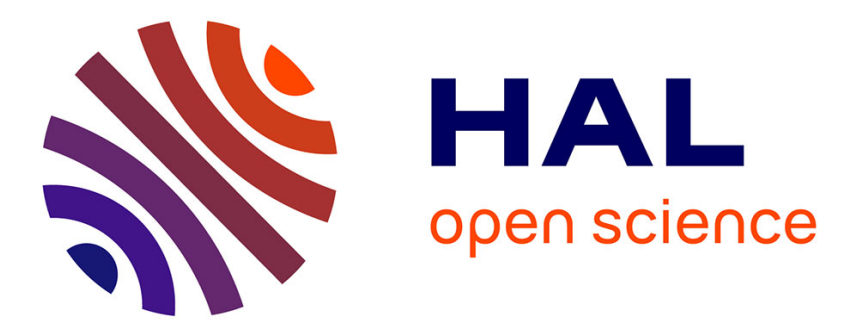

\title{
Enterprise Integration and Interoperability in Manufacturing Systems: trends and issues
}

\author{
Hervé Panetto, Arturo Molina
}

\section{To cite this version:}

Hervé Panetto, Arturo Molina. Enterprise Integration and Interoperability in Manufacturing Systems: trends and issues. Computers in Industry, 2008, 59 (7), pp.641-646. 10.1016/j.compind.2007.12.010 . hal-00259678

\section{HAL Id: hal-00259678 https://hal.science/hal-00259678}

Submitted on 28 Feb 2008

HAL is a multi-disciplinary open access archive for the deposit and dissemination of scientific research documents, whether they are published or not. The documents may come from teaching and research institutions in France or abroad, or from public or private research centers.
L'archive ouverte pluridisciplinaire HAL, est destinée au dépôt et à la diffusion de documents scientifiques de niveau recherche, publiés ou non, émanant des établissements d'enseignement et de recherche français ou étrangers, des laboratoires publics ou privés. 


\title{
Enterprise Integration and Interoperability in Manufacturing Systems: trends and issues
}

\author{
Hervé Panetto ${ }^{1}$, Arturo Molina ${ }^{2}$ \\ ${ }^{I}$ CRAN - UMR 7039, Nancy-University, CNRS, France; Herve.Panetto@cran.uhp-nancy.fr \\ ${ }^{2}$ Tecnologico de Monterrey, Mexico; armolina@itesm.mx
}

\begin{abstract}
:
Recent advances in information and communication technologies have allowed manufacturing enterprise to move from highly data-driven environments to a more cooperative information/knowledge-driven environment. Enterprise knowledge sharing (know-how), common best practices use, and open source/web based applications are enabling to achieve the concept of integrated enterprise and hence the implementation and interoperability of networked enterprises. Enterprise Integration and Interoperability in Manufacturing Systems is a key concept to face the challenges of these new environments. This paper describes challenges, trends and issues that must be addressed in order to support the generation of new technological solutions.
\end{abstract}

\section{Introduction}

Integration in Manufacturing (IiM) is the first systemic paradigm to organise humans and machines as a whole system, not only at the field level, but also, at the management and corporate levels, to produce an integrated and interoperable enterprise system. Business process software and Manufacturing Execution Systems are now available to meet the requirements of this fully computerised and automated integration. Major problems remain with respect to the interface between the enterprise corporate level and the manufacturing shop floor level, so that

Corresponding author: H. Panetto, CRAN, Nancy-University, CNRS, Faculté des Sciences et Techniques, BP 239, F-54506 Vandoeuvre-lès-Nancy Cedex, phone: +33 383684426, E-mail: Herve.Panetto@cran.uhp-nancy.fr 
management and operation decisions within a closed loop are facilitated to pace the production according to the life-cycle dynamics of the products, processes and humans inside and outside the enterprise. Today, networked business encounters recurrent difficulties due to the lack of interoperability between enterprise systems. The role of research in the field is to create upstream conditions of technological breakthrough to avoid that enterprise investment be simply pulled by the incremental evolution of IT offer. However, the future relies on collaboration networks that can be created among companies, people and societies in order to generate shared knowledge and wealth. A number of important enablers are needed to support the creation of successful collaborative networks e.g. common reference models, effective interoperability mechanisms and approaches, supporting infrastructures based on open architectures, design and engineering methodologies to instantiate/duplicate already successful cases, and standardized market technologies and tools.

Enterprise Engineering models and tools are needed for a seamless integration of Business and Manufacturing models, in order to completely describe the information aspects of an integrated manufacturing system. However, up to date, although some high level standards in the area of Enterprise modelling and integration are available; they are not yet widely recognised as such and not used in industry.

Future scenarios place Information and Communication Technologies to be core in new developments. Digital megatrends such as: e-Tailing, e-Government, Entertainment on demand, virtual education and a wide set of online services (finance, publishing, marketing) will be part of everyone life's. However all these applications and systems will require satisfying the following fundamental requirements [1]:

- Enterprise integration and interoperability

- Distributed organization

- Model-based monitor and control

- Heterogeneous environments

- Open and dynamic structure

- Cooperation

- Integration of humans with software and hardware

- Agility, scalability and fault tolerance.

The following technological areas have been defined to be core for the success of next generation manufacturing related to Information and Communication Technologies [2]:

- Adaptable, integrated equipment, processes, and systems that can be readily reconfigured

- System synthesis, modelling, and simulation for all manufacturing operations

- Technologies that can convert information into knowledge for effective decision making

- Enhanced human-machine interfaces 
- Educational and training methods that would enable the rapid assimilation of knowledge

- Software for intelligent systems for collaboration

- Product and process design methods that address a broad range of product requirements

- Innovative processes to design and manufacture new materials and components

- Manufacturing processes that minimize waste production and energy consumption

All of these areas are strongly related to the concepts of Enterprise Integration and Interoperability, and therefore it is important to foster the application these concepts to support the generation of new technological solutions.

This paper summarizes the need for Enterprise Integration and Interoperability in Manufacturing Systems and puts forward trends and issues important and relevant for future research work. The Grand Challenges may be classified according to the following areas in [1] (Table 1):

- Collaborative Networked Organizations

- Enterprise Modelling and Reference Models

- Enterprise and Processes Models Interoperability

- Validation, Verification, Qualification and Accreditation of Enterprise Models

- $\quad$ Model Reuse and Repositories 
Table 1. Research Challenges for Enterprise Integration and Interoperability [1]

\begin{tabular}{|c|c|c|c|c|}
\hline CHALLENGES & BUSINESS & KNOWLEDGE & APPLICATIONS & $\begin{array}{l}\text { COMMUNICATIONS } \\
\text { (ICT) }\end{array}$ \\
\hline $\begin{array}{l}\text { Grand Challenge 1. } \\
\text { Collaborative Networked } \\
\text { Organizations (CNOs) } \\
{[27]}\end{array}$ & $\begin{array}{l}\text { - Business and strategy models } \\
\text { - Reference Models of CNOs } \\
\text { - Formalisms for modelling collaboration } \\
\text { networks }\end{array}$ & $\begin{array}{l}\text { - Knowledge about business processes } \\
\text { and operations in CNOs } \\
\cdot \text { Knowledge about core competencies } \\
\text { (resources based view) } \\
\text { - Sharing principles and operation rules }\end{array}$ & $\begin{array}{l}\text { - Collaborative software solutions } \\
\text { Software to simulate operation to see parallelism } \\
\text { and concurrency } \\
\text { and concurrency }\end{array}$ & $\begin{array}{l}\text { - Reliable communication networks } \\
\text { - Broadband } \\
\text { - Wireless applications }\end{array}$ \\
\hline $\begin{array}{l}\text { Grand Challenge 2. } \\
\text { Enterprise Modelling and } \\
\text { Reference Models } \\
{[11][26]}\end{array}$ & $\begin{array}{l}\text { - Enterprise measurement systems (e.g. } \\
\text { Balanced Score Card) } \\
\text { - Compensation systems based on } \\
\text { enterprise performance measures } \\
\text { - Model Driven Architectures }\end{array}$ & $\begin{array}{l}\text { - Description of Skills, Core } \\
\text { Competencies, Organization roles and } \\
\text { Knowledge assets } \\
\text { - On line resources availability and } \\
\text { capacity } \\
\text { - Balanced automatic vs. manual tasks }\end{array}$ & $\begin{array}{l}\text { - Integration of Enterprise Applications (ERP, } \\
\text { MES, SCADA, Factory Automation Systems) } \\
\text { - Workflow management systems (WfMS) } \\
\text { - Computer Supported Cooperative Work (CSCM) }\end{array}$ & $\begin{array}{l}\text { - Open platforms and architectures } \\
\text { - Human Computer Interaction } \\
\text { applications } \\
\text { - Friendly User Interfaces }\end{array}$ \\
\hline $\begin{array}{l}\text { Grand Challenge } 3 \text {. } \\
\text { Enterprise and Processes Models } \\
\text { Interoperability } \\
\text { [4] [12] }\end{array}$ & $\begin{array}{l}\text { - Integration of business information } \\
\text { - Networked enterprises } \\
\text { - Ontology mapping and matching } \\
\text { making structure }\end{array}$ & $\begin{array}{ll}\text { - } & \text { Interoperability of models } \\
\text { - Standards (KIF, KQML) } \\
\text { - Shared Ontology } \\
\text { - } \text { Explicit knowledge models } \\
\text { knowledge management system }\end{array}$ & $\begin{array}{l}\text { - Standards and Interfaces } \\
\text { - Interoperable databases } \\
\text { - Modular and Reconfigurable systems } \\
\text { in/Plug out) } \\
\text { - Simulation software }\end{array}$ & $\begin{array}{l}\text { - Standards } \\
\text { - Interfaces and mediators } \\
\text { - Interoperability }\end{array}$ \\
\hline $\begin{array}{l}\text { Grand Challenge } 5 . \\
\text { Model Reuse and Repositories } \\
\text { [19] [20] }\end{array}$ & $\begin{array}{l}\text { - Distributed business information systems } \\
\text { - Unified Database Enterprise Models }\end{array}$ & $\begin{array}{l}\text { - Ontology and formal modelling } \\
\text { - Life Cycle Management Information } \\
\text { Models }\end{array}$ & $\begin{array}{l}\text { Data Mining } \\
\text { - Databases and data warehousing } \\
\text { - Knowledge Based Systems }\end{array}$ & $\begin{array}{l}\text { - Standards } \\
\text { - Interfaces } \\
\text { - Interoperability }\end{array}$ \\
\hline
\end{tabular}




\title{
2. The need for Enterprise Integration and Interoperability solutions
}

\author{
2.1 Key concepts of Enterprise Integration and Interoperability
}

Enterprise integration is a domain of research developed since 1990's as the extension of Computer Integrated Manufacturing (CIM). Enterprise integration research is mainly carried out within two distinct research communities: enterprise modelling and Information Technology (IT). The notion of Enterprise Integration as it is understood in the frame of enterprise modelling refers to a set of concepts and approaches such as for example the definition of a global architecture of the system, the consistency of system-wide decision making (coherences between local and global objectives), the notion of the process which models activity flow beyond the borders of functions, the dynamic allocation of resources as well as the consistency of data [3].

It is to notice that enterprise integration is an essential component of enterprise engineering which concerns the set of methods, models and tools that one can use to analyze, to design and to continually maintain an enterprise in an integrated state.

In the current industrial and economic context, enterprise systems need to be constantly and smoothly re-engineered to respond to changing market demand and technological evolution. Enterprise architecture, considered as the foundation of enterprise systems engineering, has emerged as a 'tool' to help stakeholders to manage system engineering and changes. It is not only an IT issue, but first of all a strategic and organizational challenge.

However, Enterprise architecture is a challenging but still confusing concept. Compared to other fields, for example the construction industry, architecture has been used in the design and construction of all size buildings. Architects use standard symbols that can be recognized and understood by all members of their industry to carry out the construction work.

The enterprise engineering community, which is much younger, has never experienced the advantage of this type of "time tested" structure. Instead, since its beginning, many heterogeneous architecture proposals have been developed. They are often overlapping approaches and the underlying concepts are not explicitly defined. Similarities and differences between enterprise architectures cannot be perceived by users; and this creates obstacles for its correct understanding in industry and finally its acceptance and use. The lack of a generally agreed terminology in this domain is also a bottleneck for its efficient application [4].

Integration is generally considered to go beyond mere interoperability to involve some degree of functional dependence. While interoperable systems can function independently, an integrated system loses significant functionality if the flow of services is interrupted. An integrated family of systems must, of necessity, be interoperable, but interoperable systems need not be integrated. Integration also deals with organisational issues, in possibly a less formalised manner due to dealing with people, but integration is much more difficult to solve, while interoperability is more of a technical issue. Compatibility is something less than interoperability. It means that systems/units do not interfere with each other's functioning. But it does 
not imply the ability to exchange services. Interoperable systems are by necessity compatible, but the converse is not necessarily true. To realize the power of networking through robust information exchange, one must go beyond compatibility. In sum, interoperability lies in the middle of an "Integration Continuum" between compatibility and full integration. It is important to distinguish between these fundamentally different concepts of compatibility, interoperability, and integration, since failure to do so, sometimes confuses the debate over how to achieve them. While compatibility is clearly a minimum requirement, the degree of interoperability/integration desired in a joint family of systems or units is driven by the underlying operational level of those systems [5].

\subsection{Enterprise architecture in Manufacturing Systems environment}

The problems of enterprise applications interoperability can be defined according to various points of view and perspectives. These aspects correspond to modelling frameworks and enterprise architecture, with, as a common point, an implicit or explicit perspective of evolution according to a linear scale the more an application is interoperable with another and thus higher in a value scale, the more it relates to a high level of abstraction of the models and their semantics. For this reason, an interoperability development process is often classified in so-called "levels of interoperability" in the literature (Table 2) [5].

A widely recognized model for information systems interoperability is, 'Levels of Information Systems Interoperability' (LISI) [6]. LISI focuses on the increasing levels of sophistication of systems interoperability (Isolated systems, connected interoperability in a peer-to-peer environment, Functional interoperability in a distributed environment, Domain based interoperability in an integrated environment; Enterprise based interoperability in a universal environment. LISI focuses on technical interoperability and the complexity of interoperations between systems. The model does not address the environmental and organizational issues that contribute to the construction and maintenance of interoperable systems. Acknowledging this limitation, [7] proposed the Organizational Interoperability Maturity model (OIM), which extends the LISI model into the more abstract layers of command and control support (Independent, Ad hoc, Collaborative, Integrated, Unified). Beyond this organisational interoperability, the type of content of the exchange flows is also an issue. To cope with it, the NATO C3 Technical Architecture (NC3TA) Reference Model for Interoperability [8] focuses on technical interoperability and establishes interoperability degrees and sub-degrees (Unstructured Data Exchange, Structured Data Exchange, Seamless Sharing of Data, and Seamless Sharing of Information). The degrees are intended to categorize how operational effectiveness could be enhanced by structuring and automating the exchange and interpretation of data.

Moreover, at a conceptual level, [9] has developed the Levels of Conceptual Interoperability (LCIM) Model that addresses levels of conceptual interoperability that go beyond technical models like LISI. Systems interoperability is not only a technical problem (as stated by LISI or LCIM) but also deals with organisational issues (OIM). These aspects of interoperability are coherent with the definitions proposed by the European Interoperability Framework [10], which considers three aspects of interoperability (Organisational, Semantic, and Technical). 
Table 2: The maturity models [5]

\begin{tabular}{|c|c|c|c|c|c|}
\hline \multirow{3}{*}{ EIF } & & & & & Organisational \\
\hline & & & \multicolumn{3}{|c|}{ Semantic } \\
\hline & \multicolumn{5}{|c|}{ Technical } \\
\hline LISI & 0 - Isolated & 1 - Connected & $\begin{array}{l}2 \text { - Functional } \\
\text { Distributed }\end{array}$ & $\begin{array}{c}\text { 3-Domain } \\
\text { Integrated }\end{array}$ & $\begin{array}{c}4 \text { - Enterprise } \\
\text { Universal }\end{array}$ \\
\hline OIM & 0 - Independent & 1-Ad-hoc & $2-$ Collaborated & 3 - Integrated & 4-Unified \\
\hline LCIM & $0-$ System specific & 1 - Documented & 2 - Aligned static & $\begin{array}{l}3 \text { - Aligned } \\
\text { Dynamic }\end{array}$ & 4 - Harmonised \\
\hline NATO & $\begin{array}{c}1 \text { - Unstructured } \\
\text { data }\end{array}$ & 2 - Structured data & $\begin{array}{l}3 \text { - Seamless data } \\
\text { sharing }\end{array}$ & \multicolumn{2}{|c|}{4 - Seamless information sharing } \\
\hline
\end{tabular}

Choosing a framework is a necessary condition for facilitating interoperability engineering because they are representing best practices in the domain of interoperable systems engineering. For example, in Information System design approach, in order to cope with this issue, [11] proposes a key-problem framework that enables both to involve efficiently users and improve the design of a model of an integrated enterprise. These two points are developed through a cross analysis of the works related to EI in both the enterprise modelling and information system design fields.

The ultimate goal of enterprise integration is to achieve business integration to support intra and/or inter enterprise operations. However business integration needs the support of physical integration and application integration for easy communication and exchange of information. Currently physical integration has been achieved in many enterprises and application integration is also in progress in many companies. However business integration, although addressed since 1980's, is still not developed to a satisfactory level.

\subsection{Integration and Interoperability in Manufacturing Systems}

Integration of information and manufacturing systems is one of the great achievements of Enterprise Modelling. However, new factors, such as the fast evolution of Information and Communication Technologies (ICT) or the need to set up alliances among different types of enterprises quickly in order to benefit from market opportunities, are causing new types of problems, like interoperability, to appear in the Enterprise Modelling context. [12] proposes a detailed definition of a UML Profile for model transformation between GRAI Extended Actigram into UML Activity Diagram in order to deal with interoperability problems, which arise in collaborative enterprises at the Enterprise Modelling level when they try to follow a model-driven approach. The final objective of performing this profile is to achieve a Model Driven Interoperability solution that can start out from enterprise models and guide enterprises to obtain Enterprise Software Applications. One of the main advantages of the approach based on UML Profiles is that it provides enterprises with a common solution to model and use their own business domain in a modeldriven way, which takes interoperability into account. Moreover, in this paper we provide some other approaches that could be followed if the model transformation tools do not provide facilities for applying UML Profiles. 
MES (Manufacturing Execution Systems) solutions provide real time information about what is happening in the shop floor, for managers (under a strategic approach), and for direct operation workers (under a purely operative approach). It is also an information bridge between Planning Systems used in Strategic Production Management (such as ERP - Enterprise Resource Planning) and Manufacturing Floor Control SCADA (Supervisory Control and Data Acquisition). It links the Manufacturing Information System's layers (Strategic Planning and Direct Execution) through the adequate on - line managing and control of updated information related with the basic enterprise resources: people, inventory and equipment [13]. The enormous importance acquired by MES resides, in a significant percentage, on its functionalities (implying people, inventory and equipment) and their interaction with the compounding elements of the industrial plant environment. Core functions of MES include Planning System Interface, Data Collection, Exception Management, Work Orders, Work Stations, Inventory / Materials and Material Movement. MES supporting functions could include the following Genealogy, Maintenance, Time and Attendance, Statistical Process Control, Quality Assurance, Process Data and Documentation Management. However, there is an increasing need to provide support defining and implementing an interoperability relationship between these manufacturing software and business applications such as ERP systems.

In order to support the requested Business to Manufacturing (B2M) interoperation, the standard IEC 62264 [14] defines models and establishes terminology (semantics) for defining the interfaces between an enterprise's business systems and its manufacturing control systems. It describes in a rather detailed way the relevant functions in the enterprise and the control domain and the objects normally exchanged between these domains. It is becoming the accepted model for B2M integration and interoperability. In this context, the main modelling concept is to make the product interactive as the 'controller' of the manufacturing enterprise's resources for enabling 'on the fly' interoperability relationships between existing product-systems and ensuring coherence between the physical and information flows all through the product life-cycle (Figure 1) [15].

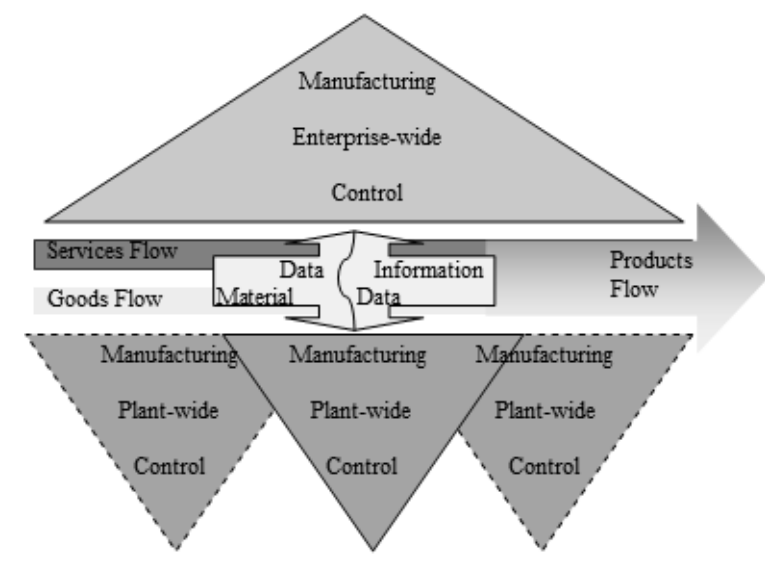

Figure 1. Product-driven manufacturing enterprise-wide control [15] 
Information can be embedded in physical objects according to the HMS (Holonic Manufacturing System) paradigm, in order to ensure the traceability of customized products, goods for manufacturing issues and services for logistics issues [16]. Such a holonic approach requires aggregating separate object views and constructs of the IEC 62264 standard in order to define the relevant holons field, lack of established standards, which sometimes happen after the fact, and the rapid and unstable growth of the basic technology with a lack of commonly supported global strategy [17].

Enterprise Integration engineering can then concern different levels and be approached from different perspectives. At the sub-enterprise level, the functionality of the integrated application or system is limited to a relatively homogeneous area, typically a single local site under a single ownership. For example, flexible manufacturing systems are at the integrated sub-enterprise level. Complete functional integration at the single-site enterprise level assures that business processes, manufacturing processes and product realization are united using a common architecture to fulfil a common goal. This is most likely for a single plant under single ownership, such as an automated factory.

The final achievement of Enterprise Integration Engineering is to integrate at all levels different types of e-technologies (Telecommunications, Internet/Intranet/Extranet, Database, Web Applications), e-applications (ERPEnterprise Resource Planning, MES - Manufacturing Execution System, SCI Supply Chain Integration, EPS-Electronic Procurement Systems, CRM - Customer Relationship Management, SRM - Supplier Relationship Management) and eservices (e-Supply, e-Engineering, e-Marketing, e-Brokerage, e-Productivity, eFactory) in order to create the concept of e-Enterprise [18].

\section{SEMANTICS ISSUES IN MANUFACTURING ENTERPRISE INTEGRATION AND INTEROPERABILITY}

Because of the current trend of integration and interoperability of industrial systems, their size and complexity continue to grow making it more difficult to analyze, to understand and to solve the problems that happen in their organizations. Continuous improvement methodologies are powerful tools in order to understand and to solve problems, to control the effects of changes and finally to capitalize knowledge about changes and improvements. These tools involve suitably represent knowledge relating to the concerned system. Consequently, Knowledge Management (KM) is an increasingly important source of competitive advantage for organizations. Particularly, the capitalization and sharing of knowledge resulting from experience feedback are elements which play an essential role in the continuous improvement of industrial activities. In this paper, the contribution deals with semantic interoperability and relates to the structuring and the formalization of an Experience Feedback (EF) process aiming at transforming information or understanding gained by experience into explicit knowledge. The reuse of such knowledge has proved to have significant impact on achieving the missions of companies. However, the means of describing the knowledge objects of an experience generally remain informal. Based on an experience feedback process model and conceptual graphs, 
this paper takes domain ontology as a framework for the clarification of explicit knowledge and know-how, the aim of which is to get lessons learned descriptions that are significant, correct and applicable [20].

In Manufacturing Enterprise Integration there are two types of architectures. Type 1 describes an architecture or physical structure of some component or part of the integrated system such as the computer system or the communications system. Type 2 presents an architecture or structure of the project which develops the physical integration, i.e., those that illustrate the life cycle of the project developing the integrated enterprise. Today, the architecture concept is not sufficiently exploited. One of the reasons is the lack of proper architecture representation formalism supporting significant characterization of features and properties of enterprise systems. Therefore the review of the past and recent enterprise architecture approaches clearly shows the insufficient development of type 1 architectures, in particular the reference architectures at higher abstraction level are needed. This would help reuse of mature architecture solution (types) to save time and cost while performing enterprise engineering and integration projects. There is also a need to harmonise and map existing type of architectures (frameworks for enterprise integration and/or interoperability).

The following research issues are considered challenging for the next years to come:

- Enterprise architecture needs addressing more on how to align of business strategy to technology for implementation, and not just focused on business or IT with separated research and development

- It is necessary to develop an Enterprise architecture language at a high level of abstraction for representing enterprise architectural structure, characteristics and properties at early stage of design.

- Existing architecture design principles and patterns were not developed to a satisfactory level to allow bringing significant improvement to enterprise architecting. More research is also needed in this area to promote the reuse of good practices and theories.

- The development of an ontology precisely defining concepts and properties of enterprise architecture domain is challenging. This ontology is needed to allow a clear understanding of the universe of discourse in this domain and avoid multiple and sometimes redundant developments of architectural proposals. Enterprise architecture ontology also contributes to semantic interoperability between different enterprise architecture proposals.

The goal is then clearly to assume and to improve the correctness, the completeness, the relevance and more globally the level of quality and the level of confidence of a given model. Indeed, following the well known Model Driven Engineering principles, engineering projects, whatever may be their goal (software development, integration, risk analysis, business and organisational interoperability analysis and amelioration in a network of enterprises) manipulate models from different natures and covering different objectives. Then, system engineering provides integration, verification, validation and qualification processes all along the life cycle of a system [22]. In the same way, lot of works in information software engineering and 
integration domain provides formal techniques and tools in order to fulfil these activities [23][24][25].

\section{CONCLUSIONS}

Nowadays, semantic integration constitutes an important approach to deal with heterogeneity within large and dynamic enterprises. Currently, the existing solutions are mainly based on the use of some standards and also middleware in order to overcome the integration problem. These solutions generally fail as they do not scale to large number of applications and also fail as they do not provide more flexibility and agility. Here, solutions based on semantic web services are promising and they are being actively researched. These technologies can offer answers to some key challenges such as semantic mediation and interoperation [26].

Developments of information and communication technologies (ICTs) and turbulent market conditions have forced small and medium size enterprises (SMEs) to adapt their way of undertaking business, from traditional practices to e-business. In this context, new forms of collaboration have emerged, such as Collaborative Networks (CNs) [1] or virtual enterprises (VEs). In a collaborative networked environment (CNE), the integration and interoperability enhance the competitive advantages of the CNs and their member organizations. In this context, they become critical goals towards achieving their business objectives in a time, quality and cost effective manner [27].

\section{REFERENCES}

[1] Molina A., Panetto H., Chen D., Whitman L., Chapurlat V., Vernadat F.B. Enterprise Integration and Networking: Challenges and Trends. Studies in Informatics and Control. 16/4. 353-368. December 2007, Informatics and Control Publications. ISSN 1220-1766

[2] Nof S.Y., Morel G., Monostori L., Molina A., Filip F. From plant and logistics control to multi-enterprise collaboration: Milestone report of the Manufacturing \& Logistics Systems Coordinating Committee, Annual Reviews of Control, 30/1, 55-68, September 2006

[3] Vernadat, F.B. Enterprise Modeling and Integration (EMI): Current Status and Research Perspectives. Annual Reviews in Control. 26/1, 15-25, 2002

[4] Chen D., Doumeingts G., Vernadat F. Architectures for Enterprise Integration and Interoperability: Past, Present and Future. In: Special issue on Enterprise Integration and Interoperability in Manufacturing Systems, A. Molina and H. Panetto (Eds). Computers In Industry, 59/5, May 2008, Elsevier

[5] Panetto H. Towards a Classification Framework for Interoperability of Enterprise Applications. International Journal of CIM, 20/8, 727-740, Taylor \& Francis, December 2007, ISSN 0951-192X. 
[6] C4ISR Architectures Working Group report. Levels of Information Systems Interoperability (LISI), DoD, February 1998, Washington, DC.

[7] Clark, T. and Jones R.. Organisational Interoperability Maturity Model for C2, In Proceedings of the Command And Control Research And Technology Symposium (CCRTS), June 29, July 1, 1999. Newport, RI, USA

[8] NATO Allied Data Publication 34 (ADatP-34). NATO C3 Technical Architecture (NC3TA), Version 4.0. 2003

[9] Tolk, A. Beyond Technical Interoperability - Introducing a Reference Model for Measures of Merit for Coalition Interoperability. In Proceedings of the 8th International Command and Control Research and Technology Symposium (ICCRTS), Washington, DC, June 17-19, 2003. Washington DC: Command and Control Research Program (CCRP), 2003.

[10] EIF, European Interoperability Framework for pan-European eGovernment Services, Interoperable Delivery of European eGovernment Services to public Administrations, Businesses and Citizens (IDABC), November, Luxembourg.

[11] Goepp V., Kiefer F., Avila O. Information System Design and integrated Enterprise Modelling through key-problems. In: Special issue on Enterprise Integration and Interoperability in Manufacturing Systems, A. Molina and $\mathrm{H}$. Panetto (Eds). Computers In Industry, 59/5, May 2008, Elsevier

[12] Roque M., Vallespir B., Doumeingts G. Interoperability in enterprise modelling: Translation, elementary constructs meta-modelling and UEML development. In: Special issue on Enterprise Integration and Interoperability in Manufacturing Systems, A. Molina and H. Panetto (Eds). Computers In Industry, 59/5, May 2008, Elsevier

[13] Mejía R., López A., Molina A. Experiences in developing collaborative engineering environments: an action research approach, Computers In Industry, 58/4, 329-346, May 2007, Elsevier

[14] IEC 62264 (2002). IEC 62264. Enterprise-control system integration, Part 1. Models and terminology, Part 2: Model object attributes. ISO/IEC, Geneva

[15] Morel, G., Panetto, H., Zaremba, M-.B., Mayer, F. Manufacturing Enterprise Control and Management System Engineering: paradigms and open issues. Annual Reviews in Control. 27/2, 199-209, December 2003, Elsevier

[16] Tursi A., Panetto H., Morel G., Dassisti M. Ontology-Based Products Information Interoperability in Networked Manufacturing Enterprises. Proceedings of the IFAC CEA'2007 conference on Cost Effective Automation in Networked Product Development and Manufacturing, October 5-7, 2007, Monterrey, Mexico.

[17] Morel G., Panetto H., Mayer F., Auzelle J.-P. System of Enterprise-Systems Integration Issues: an Engineering Perspective. Invited plenary paper. Proceedings of the IFAC CEA'2007 conference on Cost Effective Automation in Networked Product Development and Manufacturing, October 5-7, 2007, Monterrey, Mexico. 
[18] Molina A, Mejía R., Galeano N., Najera T, Velandia M. The HUB as an enabling IT strategy to achieve Smart Organizations, Chapter III in Integration of ICT in Smart Organizations, Istvan Mezgar (Editor), Idea Group Publishing, 2006, pp. 64-95, ISBN: 1-59140-390-1

[19] Ben Salem R., Grangel R., Bourey J.-P. Model Transformation Tools Comparison: Application for Transforming GRAI Extended Actigrams into UML Activity Diagrams. In: Special issue on Enterprise Integration and Interoperability in Manufacturing Systems, A. Molina and H. Panetto (Eds). Computers In Industry, 59/5, May 2008, Elsevier

[20] Kamsu Foguem B., Coudert T., Geneste L. Knowledge Formalization in Experience Feedback Processes: An Ontology-Based Approach. In: Special issue on Enterprise Integration and Interoperability in Manufacturing Systems, A. Molina and H. Panetto (Eds). Computers In Industry, 59/5, May 2008, Elsevier

[21] Ramírez-Santaella A. and Molina A. Achieving e-Manufacturing: Multihead Control and Web Technology for the Implementation of a Manufacturing Execution System. In: Panetto H., Goncalves R. Pereira C.E. (Eds). Special issue on E-Manufacturing and web-based technology for intelligent manufacturing and networked enterprise interoperability, Journal of Intelligent Manufacturing, 17/6, December 2006, 715-724, Springer Verlag, ISSN 09565515

[22] Chapurlat V., Braesch C. Verification, Validation, Qualification and Certification of Enterprise Models: Statements and Opportunities. In: Special issue on Enterprise Integration and Interoperability in Manufacturing Systems, A. Molina and H. Panetto (Eds). Computers In Industry, 59/5, May 2008, Elsevier

[23] Balci O. Verification, Validation and Accreditation, Proceedings of the 1998 Winter Simulation Conference, D.J. Medeiros, E.F. Watson, J.S. Carson and M.S. Manivannan (Eds). 1998

[24] Bérard B., Bidoit M., Finkel A., Laroussinie F., Petit A., Petrucci L., Schnoebelen $\mathrm{Ph}$. McKenzie P. Systems and Software verification: model checking techniques and tools, Springer, 2001

[25] Love G., Back G.. Model Verification and Validation for Rapidly Developed Simulation Models: Balancing Cost and Theory, white paper of the Project Performance Corporation (see http://www.ppc.com/). 2002

[26] Izza S., Vincent L., Burlat P. Exploiting Semantic Web Services in Achieving Flexible Application integration in the Microelectronics Field. In: Special issue on Enterprise Integration and Interoperability in Manufacturing Systems, A. Molina and H. Panetto (Eds). Computers In Industry, 59/5, May 2008, Elsevier

[27] Chituc C.-M., Toscano, C. Azevedo A. Interoperability in Collaborative Networks: major independent and domain initiatives - The case of shoe manufacturing domain. In: Special issue on Enterprise Integration and 
Interoperability in Manufacturing Systems, A. Molina and H. Panetto (Eds). Computers In Industry, 59/5, May 2008, Elsevier 